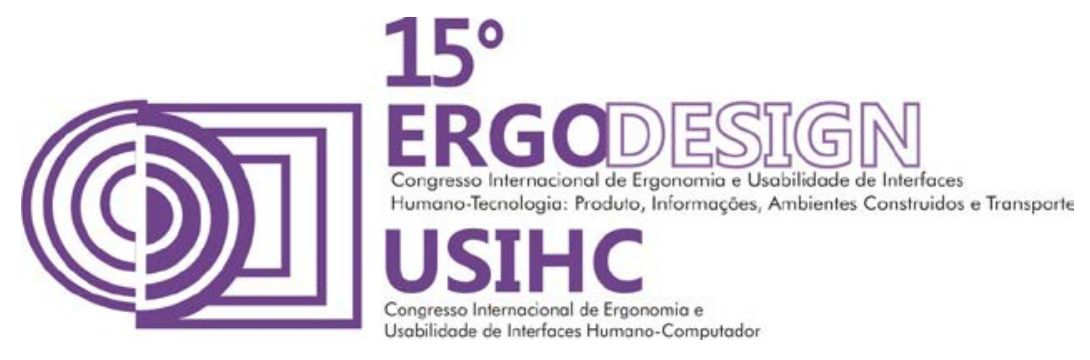

\title{
REDESIGN DO DISPENSADOR DE PAPEL DE MASCARAMENTO UTILIZADO EM FUNILARIA E PINTURA COM BASE NOS CONCEITOS DE ERGONOMIA
}

\section{REDESIGN OF MASKING PAPER DISPENSER USED IN DENT REMOVAL-PAINTING BASED ON ERGONOMICS CONCEPTS}

\author{
ELIAS, Julio Cesar (1); \\ BORTOLIN, Anderson Ricardo (2); \\ FERNANDES, Fabiane Rodrigues (3) \\ (1) FAAL, Bacharel em Design de Produto \\ e-mail:julioceliass@hotmail.com \\ (2) FAAL, Prof. MSc. do Curso de Design \\ e-mail:arbortolin@live.com \\ (3) FAAL, Prof. MSc. do Curso de Design / PPGDesign - UNESP Bauru \\ e-mail:fabyfernandes@gmail.com
}

\begin{abstract}
RESUMO
Este artigo apresenta o projeto de redesign do dispensador de papel utilizado em oficinas de funilaria e pintura com base nos conceitos Ergonomia, levando em consideração a postura exercida pelo profissional. O contexto demonstra a importância da Ergonomia em relação à saúde e bem estar do profissional. Assim, o presente projeto visa apresentar aos proprietários de oficinas do ramo de funilaria e pintura melhorias aos seus funcionários. Desta forma, fica demonstrado que o desenvolvimento do resultado final não depende tão somente do funcionário, mas sim de ferramentas e equipamentos adaptados e adequados de forma que possam realizar suas funções com exatidão e sem erros.
\end{abstract}

Palavras-chave: Design, ergonomia, mascaramento

\section{ABSTRACT}

This paper presents the redesign project of the dispenser of paper used in auto body and paint shops based on the concepts Ergonomics, taking into account the position exerted by the professional. The context shows the importance of ergonomics in relation to health and wellness professional. Thus, this project aims to present to the owners of bodywork branch workshops and painting improvements to its employees. Thus, it is shown that the development of the final result does not depend solely official, but 


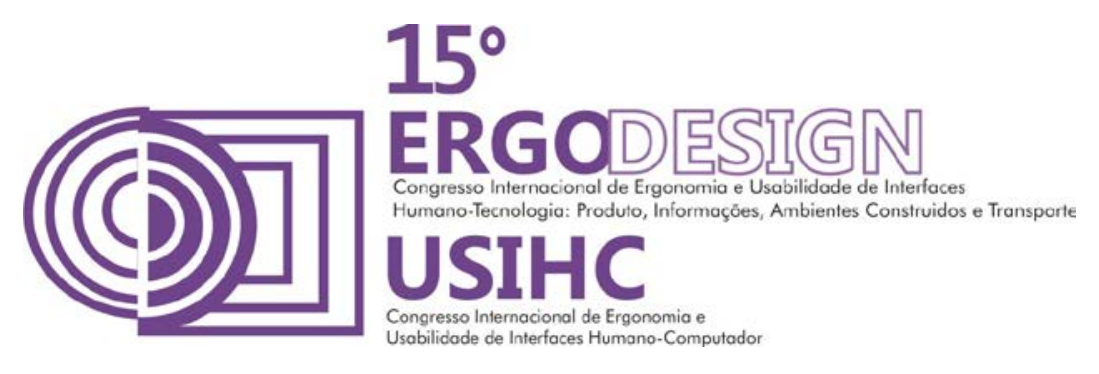

tools and adapted and appropriate equipment so they can perform their duties accurately and without errors.

Keywords: Design, Ergonomic, masking

\section{INTRODUÇÃO}

Atualmente deparamos com veículos de várias marcas e vários tons de cores, que quando menos se espera pode-se envolver em algum acidente que levará esses veículos a passarem por um processo de repintura automotiva.

A repintura automotiva surge através da identificação da pintura original do veículo, ou melhor, quando é feito o reparo de um carro, a pintura tem que ficar o mais próximo do padrão original do veículo, isso ocorre pela menor complexidade do processo, etapas e até a maneira de aplicação dos produtos.

Segundo Cardoso (2012), atualmente no Brasil a indústria automobilística se esforça em elevar as vendas de veículos nacionais, com a estimativa de atingir cada vez mais seus objetivos conforme se passa o ano, através do ritmo acelerado diante de seu crescimento.

Ainda segundo Cardoso (2012, p. 59-60) "todo processo de aperfeiçoamento e evolução de produtos ocorre com a contribuição dos usuários. [...] Buscamos sempre informações dos profissionais de reparação automotiva, os quais, cotidianamente, sentem as necessidades do mercado".

Dentro das oficinas e concessionárias observa-se que 0 dispensador de papel de mascaramento (figura 1), no processo de repintura, é a etapa mais demorada por conta de seu manuseio e de questões ergonômicas, afetando o desempenho do profissional.

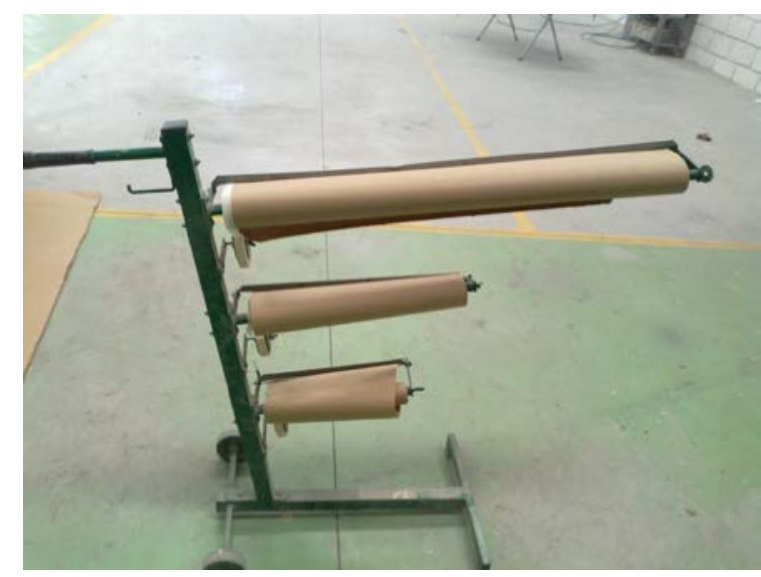

Figura 1 - Dispensador de papel de mascaramento. Fonte: Do autor (2013) 


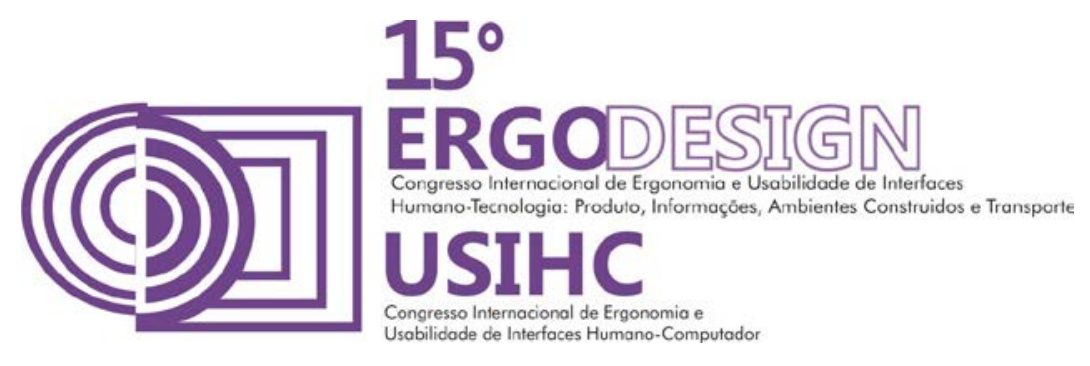

Para realizar o mascaramento de um veículo é necessário retirar o papel do dispensador, fixar a fita no papel e, depois, mascarar o veículo. Com base nessas informações, visou-se um estudo para o redesign deste equipamento, com base na Ergonomia, a fim de adaptar o artefato aos seus usuários, tornando o equipamento mais fácil de usar, de forma eficiente, sem necessidade de constrangimentos aos funcionários de oficinas.

O projeto tem como objetivo analisar a Ergonomia do dispensador de papel mascaramento em relação a postura que o profissional exerce ao manuseá-lo, resultando no redesign do produto, visando à questão da saúde e bem estar do profissional na área de repintura automotiva. As oficinas onde está sendo analisados os dispensadores são: Dimensão Funilaria e Pintura situada na cidade de Mogi Guaçu e a Funilaria e Pintura Felício Belli situada na cidade de Espirito Santo de Pinhal.

\section{FUNDAMENTAÇÃO TEÓRICA}

Atualmente nos deparamos com diversos problemas no nosso dia a dia relacionado à Ergonomia que passam despercebidas e quando nos damos conta o problema é mais sério do que se imagina. Dull e Weerdmeester (2012, p.15) dizem que "A Ergonomia pode contribuir para solucionar um grande número de problemas sociais relacionados com saúde, segurança, conforto e eficiência e que muitas situações de trabalho e da vida cotidiana são prejudiciais à saúde. As doenças do sistema músculo esquelético (principalmente dores nas costas), e aquelas psicológicas (estresse, por exemplo) constituem a mais importante causa de absenteísmo ${ }^{1}$ e de incapacitação ao trabalho. Essas situações podem ser atribuídas ao projeto ruim e ao uso incorreto de equipamentos, sistemas e tarefas. Reconhecendo isso, muitos países já obrigam os serviços de saúde a empregar ergonomistas".

Vasconcelos et al., (2011) acreditam que devido à falta de informação corretas, muitos trabalhadores de oficinas mecânicas exercem atividades que podem oferecer grandes riscos a sua saúde como postura inadequada, utilização de produtos químicos sem uso de EPIs, entre outros.

Para Savariz (1994) os fatores ergonômicos são aqueles que interferem nas características psicofisiológicas do trabalhador, causando desconforto ou afetando sua saúde. Alguns fatores ergonômicos que causam problemas ao trabalhador, muito comuns em oficinas mecânicas são: o levantamento de peso, ritmo excessivo de trabalho, monotonia, repetitividade, postura inadequada de trabalho, entre outros.

Os riscos ergonômicos podem gerar distúrbios psicológicos e fisiológicos e provocar sérios danos à saúde do trabalhador porque produzem alterações no organismo e estado emocional, comprometendo sua produtividade, saúde e segurança. (SAVARIZ,1994)

O termo absenteísmo ou absentismo é usado para designar a ausência ao trabalho por qualquer razão: doenças, acidentes de trabalho, direitos legais (doação e sangue, licença maternidade, etc.), fatores sociais (doença de parentes, por exemplo), fatores culturais extras ou intra-empresariais (emendar feriados, copa do mundo, feriados religiosos não oficiais, legalização de uma falta gerada por outra motivação não relacionada à saúde, etc.). Disponível em: <http://rhpresence.wordpress.com/2010/06/07/gestao-do-absenteismo-2/>. Acesso em: 11 abr. 2013 


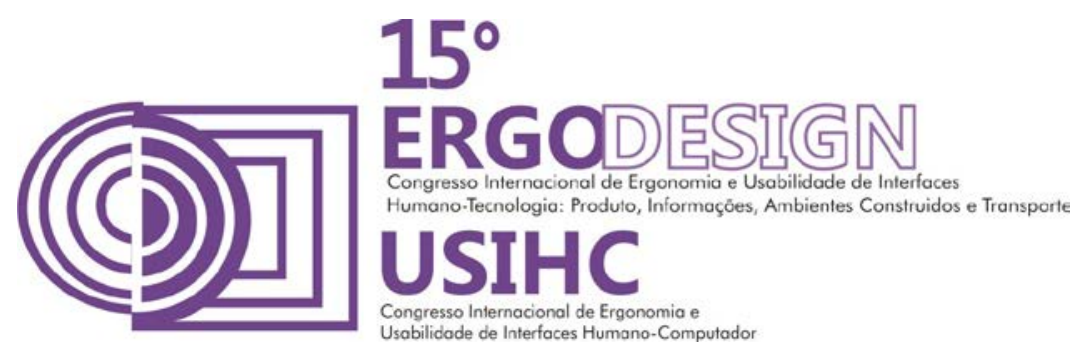

A Ergonomia deve atender aos objetivos sócios (bem-estar) e econômicos (desempenho) mantendo uma visão ampla de modo que contribua na redução dos custos, onde os custos sociais incluem o tratamento das doenças, a perda da produtividade e o absenteísmo de acordo com Dull e Weerdmeester (2012).

Nas empresas, a Ergonomia pode contribuir para melhorar a competitividade. Com uma boa adaptação ergonômica dos postos de trabalho e dos sistemas. Conforme Savariz (1994) para evitar que estes riscos comprometam as atividades e a saúde do trabalhador, é necessário um ajuste entre as condições de trabalho e o homem, sob os aspectos da praticidade e do conforto físico e psíquico por meio de: melhoria no processo de trabalho, melhores condições no local de trabalho, modernização de máquinas e equipamentos, melhoria no relacionamento entre as pessoas, alteração no ritmo de trabalho, ferramentas adequadas e postura adequada.

\section{DESENVOLVIMENTO}

\subsection{Metodologia}

O projeto é caracterizado como um estudo de campo, que através do resultado de observações e análises gerou-se um redesign do dispensador de papel de mascaramento, muito utilizado em funilarias. O projeto de divide em dois momentos: coleta de informações, através da análise do produto e procedimento de uso; e, também um questionário com os funcionários locais das duas funilarias já citadas: Dimensão Funilaria e Pintura situada na cidade de Mogi Guaçu e a Funilaria e Pintura Felício Belli situada na cidade de Espirito Santo de Pinhal, ambas no estado de São Paulo. E, desenvolvimento do novo produto, o redesign do dispensador utilizando-se a metodologia de Lobach (2001).

\subsubsection{Coleta de Dados}

\section{Análise do produto e procedimento de uso}

Segundo lida (2005), "A análise das atividades refere-se ao comportamento do trabalhador, na realização de uma tarefa". Ou seja, "a maneira como o trabalhador procede para alcançar os objetivos que the foram atribuídos". "Ela resulta de um processo de adaptação e regulação entre os vários fatores envolvidos nos trabalhos". Soares (1999), ainda coloca-se que ao realizar determinada tarefa o homem coloca em funcionamento mecanismos de adaptação e regulação que permitirão a sua realização.

O dispensador de papel é uma ferramenta fundamental no processo de repintura automotiva, que proporciona a sustentação da bobina de papel de mascaramento aumentando a produtividade do profissional na realização do mascaramento do veículo. Para maior agilidade no processo de repintura usa-se o dispensador móvel.

Os dispensadores comercializados por lojas de ferramentas são do tipo carrinho com rodízio e têm como material o aço com as dimensões de 1,200 mm comprimento, 1,020 mm altura e 550 $\mathrm{mm}$ de largura e compõe três suportes que dispensa os papeis de mascaramento com as medidas de $30 \mathrm{~cm}, 45 \mathrm{~cm}, 90 \mathrm{~cm}$. 


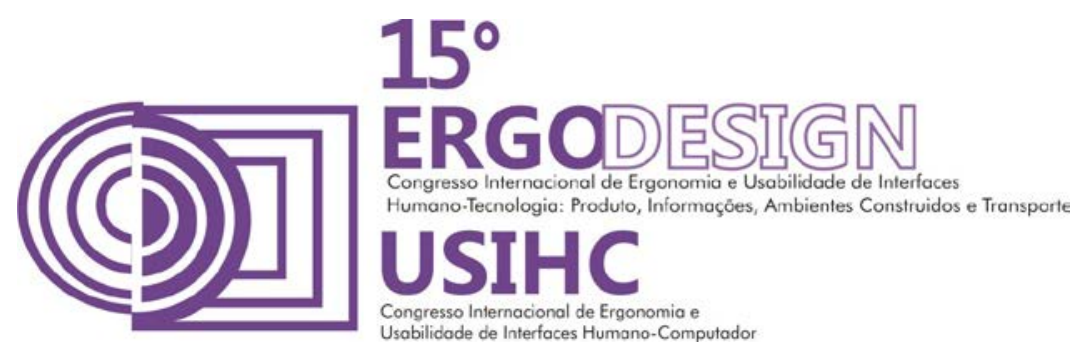

O profissional utiliza a postura flexionada (figura 2), normalmente, no momento de mascarar as peças de um automóvel, a postura é repetida entre 20 a 30 vezes por dia, levando em consideração que esse número depende muito da quantidade de carros a reparar na oficina. Essa postura afeta a coluna acarretando fortes dores nas costas levando o profissional a se afastar do trabalho devido a posição inadequada, para que não venha acontecer essa situação a ferramenta terá que passar por uma adaptação com medidas cabíveis, em que o profissional mantenha uma postura correta para o manuseio desta ferramenta.

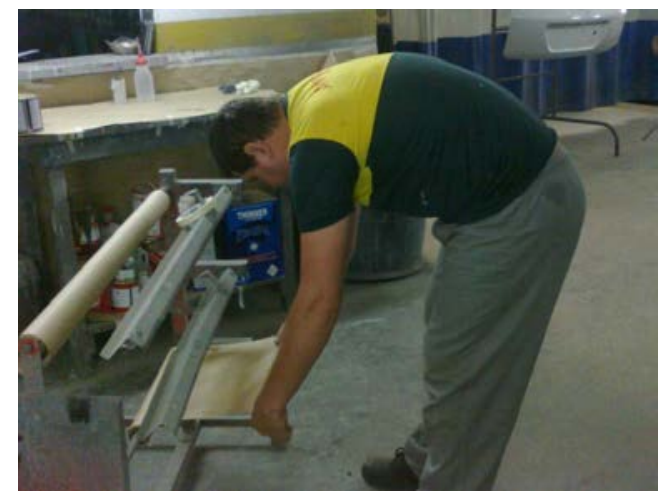

Figura 2 - Profissional em postura flexionada. Fonte: Do autor (2013)

Com relação ao destaque do papel, independente do dispensador, o profissional necessita fazer o movimento de levantar um dos braços. Na figura 3 é possível observar que ao destacar um pedaço maior de papel, o profissional estica o braço ao alto, podendo ocorrer uma lesão muscular. Algo que poderia ser feito é o reposicionamento das hastes que suporta o papel, por exemplo, deixar a haste em pé, mas em uma altura adequada ao movimento que o profissional irá realizar com o braço.

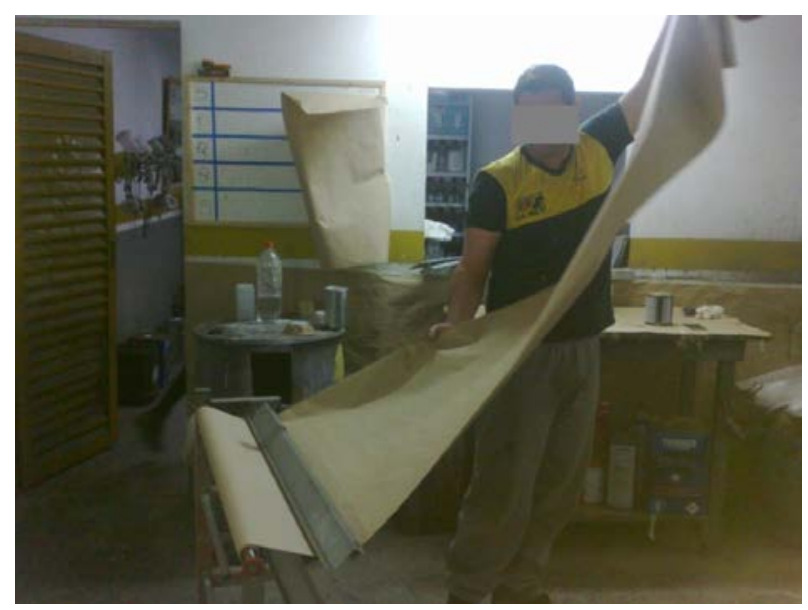

Figura 1 - Destaque do papel mascaramento.

Fonte: Do autor (2013) 


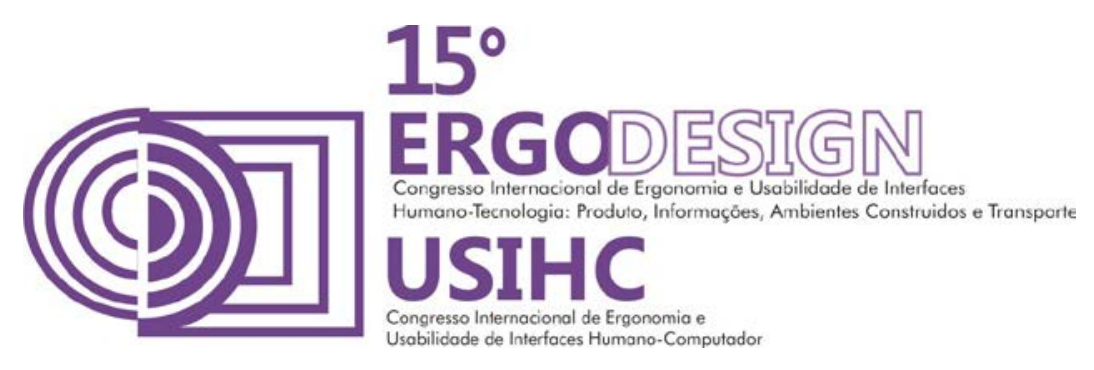

Os dispensadores de papel de mascaramento utilizados na grande maioria são móveis (figura 4). O profissional pode deslocar-se com ele de um carro para outro ganhando tempo. A pega da manivela no dispensador de papel mascaramento está de acordo com a medida que deve ser adequada aos profissionais que o manuseia que é de $3 \mathrm{~cm}$ de diâmetro e um comprimento de $10 \mathrm{~cm}$, para que possa exercer maior força com a palma das mãos.

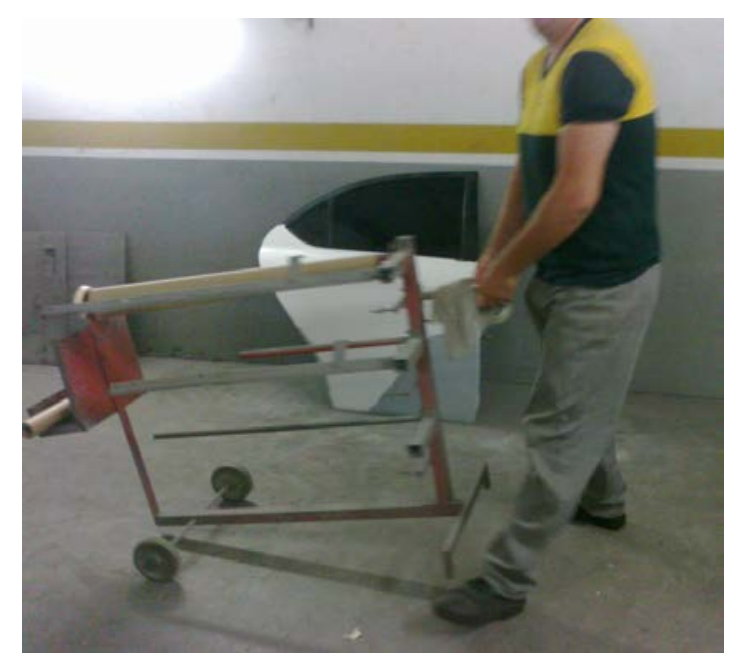

Figura 4 - Deslocamento do dispensador de papel de mascaramento. Fonte: Do autor (2013)

Na figura 5, podemos o procedimento para a troca de uma bobina de papel. O profissional tem de soltar uma porca (figura $5 \mathrm{~A}$ ) sendo mais fácil o uso de uma chave e não com as mãos. É deslocado a parte da frente do dispensador para a retirada da bobina usada (figura 5B) e em seguida adicionar uma bobina nova e voltar ao lugar (figura $5 \mathrm{C}$ ). O interessante neste caso é desenvolver, por exemplo, um sistema de encaixe das hastes pensando no peso da bobina que irá suportar, ressaltando que o processo de reparo é demorado, porém quanto mais ágil e prático for o dispensador mais o profissional irá alcançar seu objetivo com eficiência.
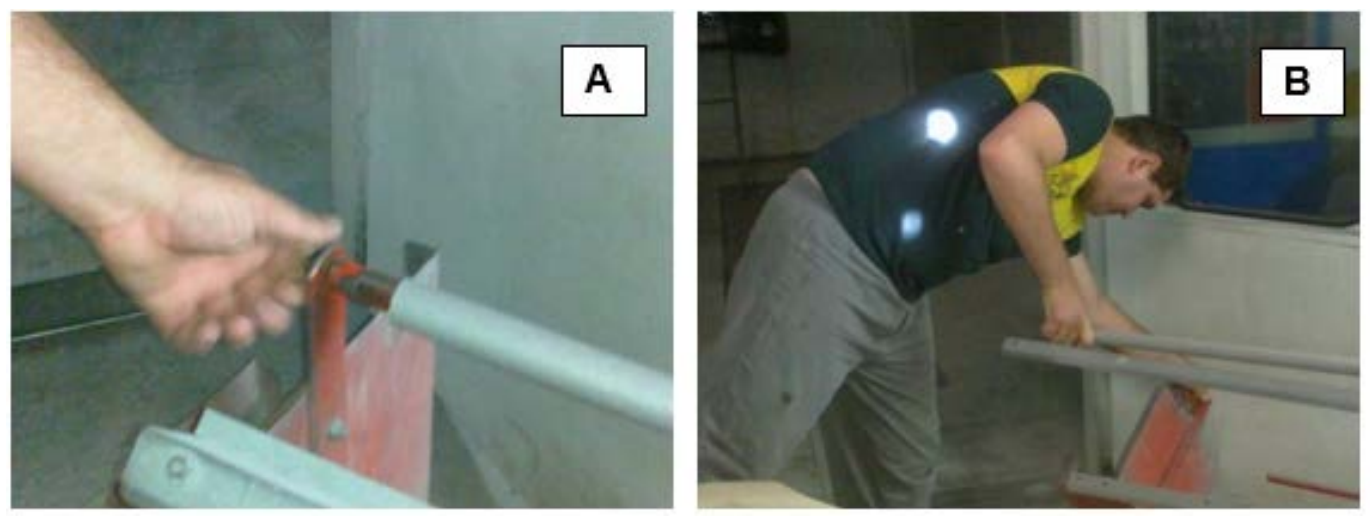

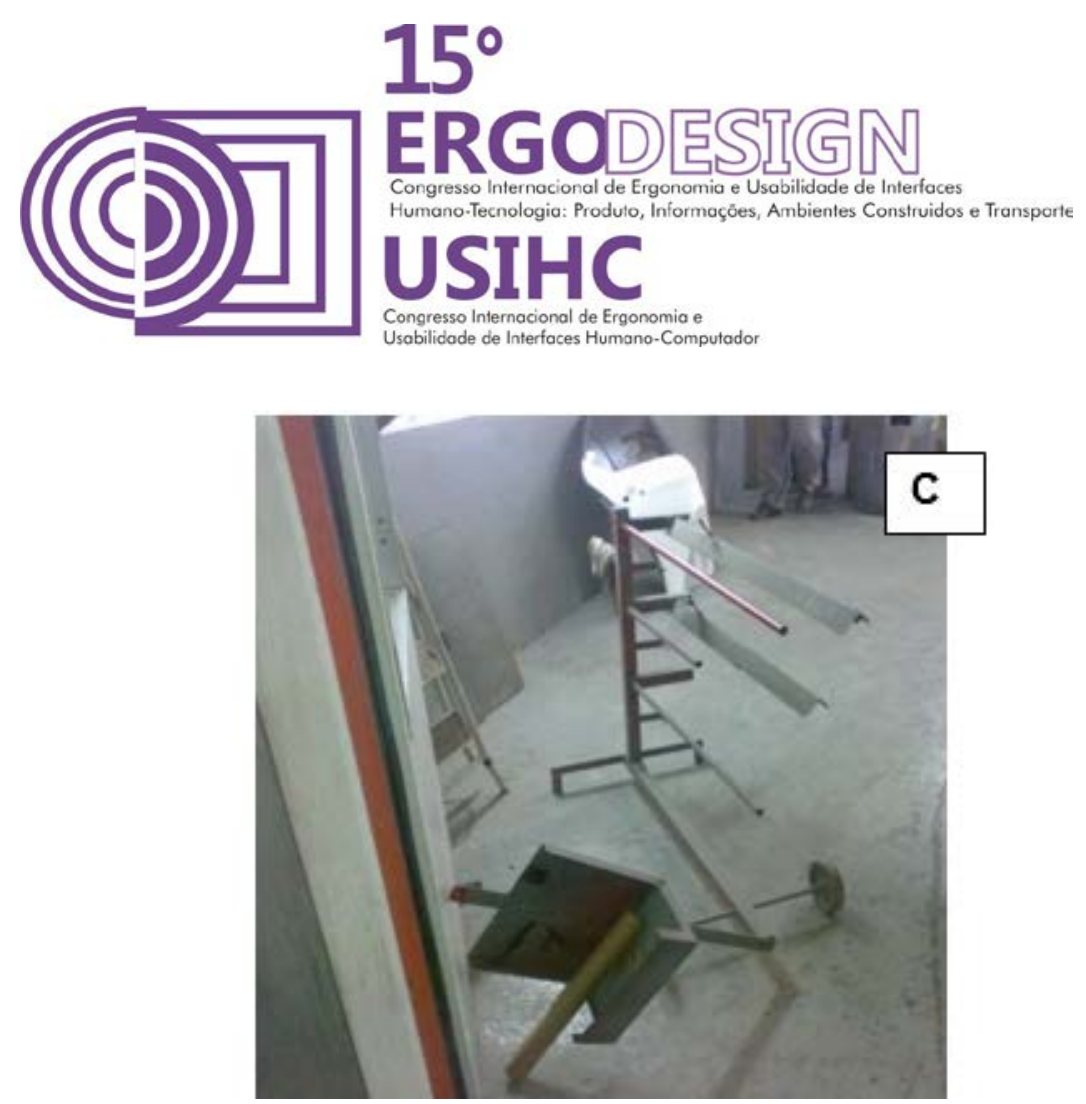

Figura 5 - Desmontagem do dispensador para a troca de bobina de papel mascaramento. Fonte: Do autor (2013)

Após essa etapa de observação, aplicou-se um questionário com os funcionários que utilizam o dispensador de papel de mascaramento.

\section{Questionário}

Para o questionário foram elaboradas 10 perguntas quantitativas (Figura 6), no qual foi aplicada em 4 cidades diferentes sendo elas: Mogi Guaçu, Mogi Mirim, Espirito Santo de Pinhal e Andradas, alcançando o total de 11 entrevistados sendo eles: 10 homens e 1 mulher. As respostas obtidas complementaram o desenvolvimento do projeto.

\section{Pesquisa Ergonômica}

Nome: Júlio Cesar Elias $\quad$ E-mail: julioceliass@hotmail.com

Projeto: Redesign do dispensador de papel de mascaramento com base nos conceitos de Ergonomia.

Empresa:

Funcionário:

Função:
Cidade:

Idade:

Tempo de Função

Continua... 


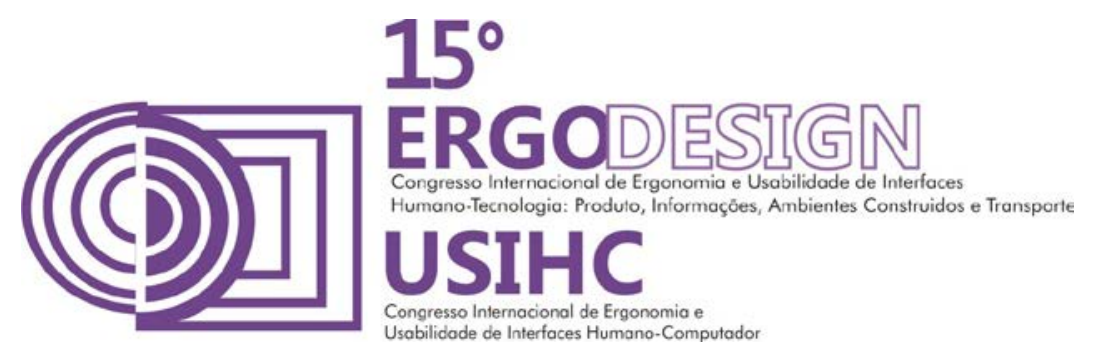

...Continuação

1) Você prefere utilizar o dispensador móvel ou manual? Por quê?

2) Você acredita que adaptações no dispensador de papel de mascaramento ajudaria a tornar o processo mais rápido?

( ) Não ( ) Sim

Quais adaptações:

3) O dispensador de papel poderia ter uma outra função?

( ) Não ( ) Sim

Qual:

4) A questão da pega do dispensador, você acha que poderia ter 2 pega, assim equilibrando as forças ao executar a tarefa?

( )Não( ) Sim

Observações:

5) Na sua opinião o que poderia ser mudado no dispensador de papel de mascaramento vendido hoje no mercado?

( ) Estrutura（ )Forma ( ) Outros ( ) não há mudanças fazer

Qual:

6) O dispensador de papel de mascaramento ocupa muito espaço no seu local de trabalho?

\section{( ) Não( ) Sim}

7) Você acha que a redução no peso das ferramentas (exceto no caso de ferramentas de bater) proporcionaria um manejo mais confortável?

（）Não（） Sim

Observações:

8) Você acha que se colocar os materiais, ferramentas e controle utilizados com maior frequência em uma área de fácil alcance facilitaria?

（） Não（） Sim

Continua... 


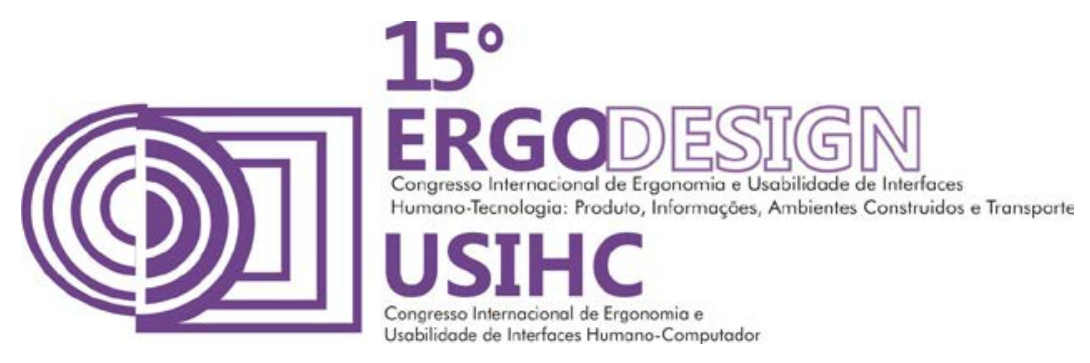

...Continuação

Observações:

9) Você acha que no dispensador de papel de mascaramento, a grossura do cabo, o comprimento e a forma está adequada a um manejo confortável?

( ) Não ( ) Sim

10) Inspecionar e fazer a manutenção regular do dispensador de papel de mascaramento. Propõe algo usável ou ágil?

( ) Não ( ) Sim

Qual:

Figura 2 - Questionário para a pesquisa ergonômica.

Fonte: Do autor (2013)

Com relação aos resultados obtidos, 82\% acredita que adaptações no dispensador ajudaria a tornar o processo mais rápido, $64 \%$ acreditam que o dispensador não necessita de outra função e que duas pegas ajudaria no uso e ainda que esse produto atual, vendido no mercado, necessita de mudanças e que o produto necessita de redução de peso. Todos os entrevistados não acham que o dispensador atual ocupa muito espaço em seus locais de trabalho, mas acreditam que os materiais, ferramentas e controles utilizados com maior frequência devem permanecer em uma área de fácil acesso. $73 \%$ dos entrevistados estão satisfeitos com a forma, espessura e comprimento do cabo.

\subsubsection{Desenvolvimento de produto}

Segundo Lobach (2001), no processo de design pode-se dizer que existem duas variáveis, podendo ser tanto processo criativo onde o designer irá utilizar todo seu raciocínio, sua imaginação e suas ideias para desenvolver um produto ou uma ação que atenda às necessidades das pessoas ou como um processo de solução de problema que através destas ideias o designer irá solucionar de uma forma concretizada agregando todo o valor que atenda tanto as necessidades como a satisfação das pessoas. Lobach (2001, p.141), ainda ressalta que "como o processo de design pode se desenvolver de forma extremamente complexa (dependendo da magnitude do problema) nos parece útil, para fins didáticos, dividi-lo e quatro fases distintas, embora estas fases nunca sejam exatamente separáveis no caso real. Elas se entrelaçam umas ás outras, com avanços e retrocessos".

Para o desenvolvimento do projeto será baseada na metodologia de Lobach (2001), com base nas 4 fases do processo criativo que irão dar uma orientação para a realização e solução do problema apresentado, sendo essas fases: 


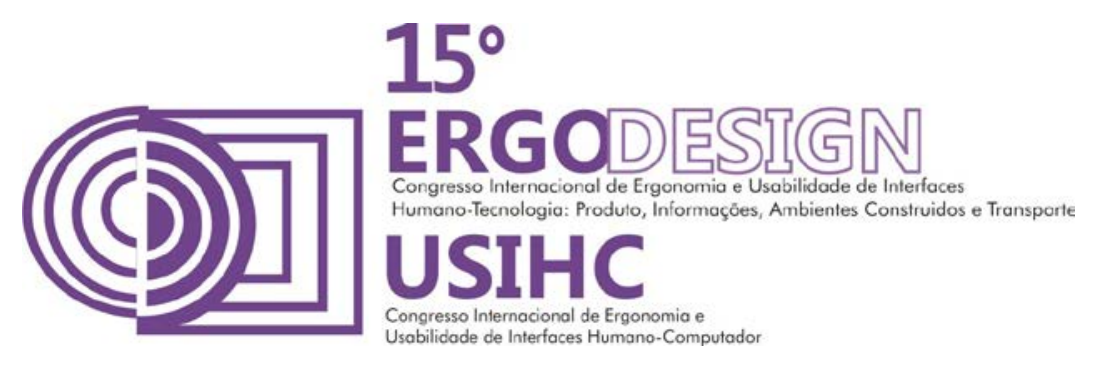

- Fase 01 - Preparação: nesta fase através da determinação do problema, público-alvo, análise de mercado e da atividade buscou-se coletar dados e informação para a realização da etapa seguinte;

- FASE 02 - Geração de ideias: após a coleta de dados gerou-se os conceitos, requisitos do projeto para assim dar início a criação de propostas;

- FASE 03 - Avaliação das alternativas: verificando a mais viável e que mais se encaixa nos conceitos e requisitos determinados pelo projeto;

- FASE 04 - Realização: fase de desenvolvimento do produto (desenho técnico, desenho de apresentação, mock-up e relatório do produto.

\section{RESULTADO}

Após concluir as etapas foi possível chegar a um modelo (figura 7) para o redesign do dispensador de papel de mascaramento. A figura 8 apresenta detalhes do produto.

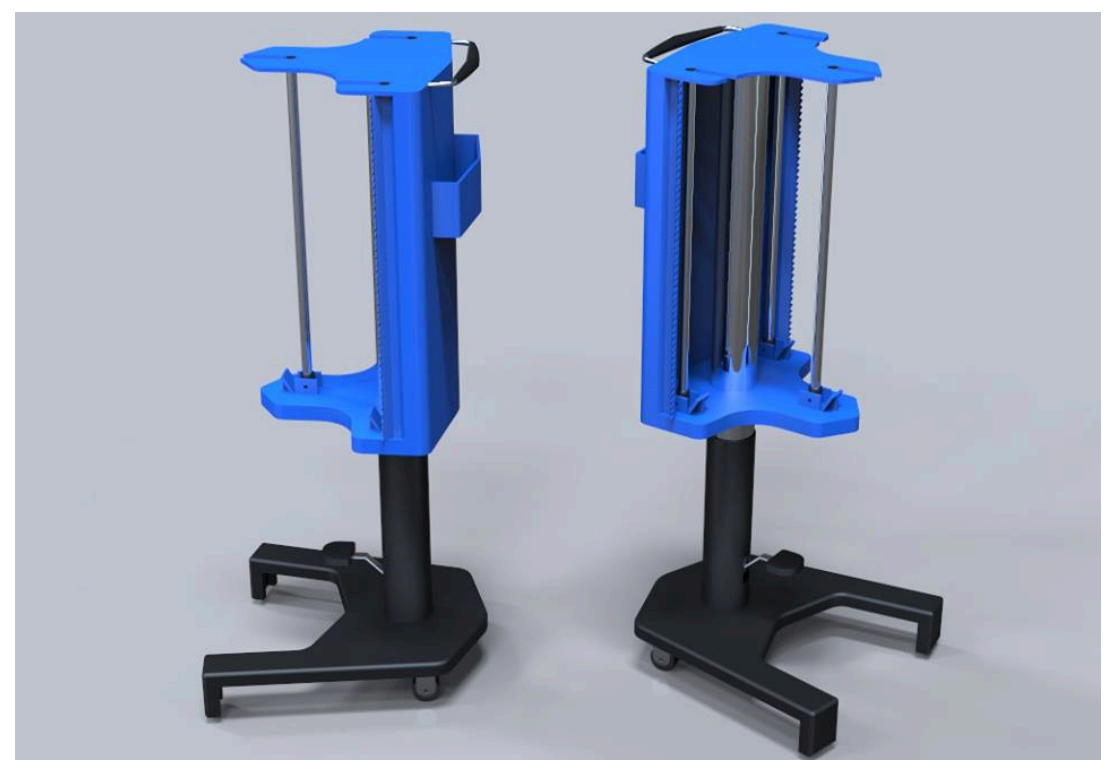

Figura 7 - Dispensador de papel de mascaramento em 3D.

Fonte: do autor (2013) 

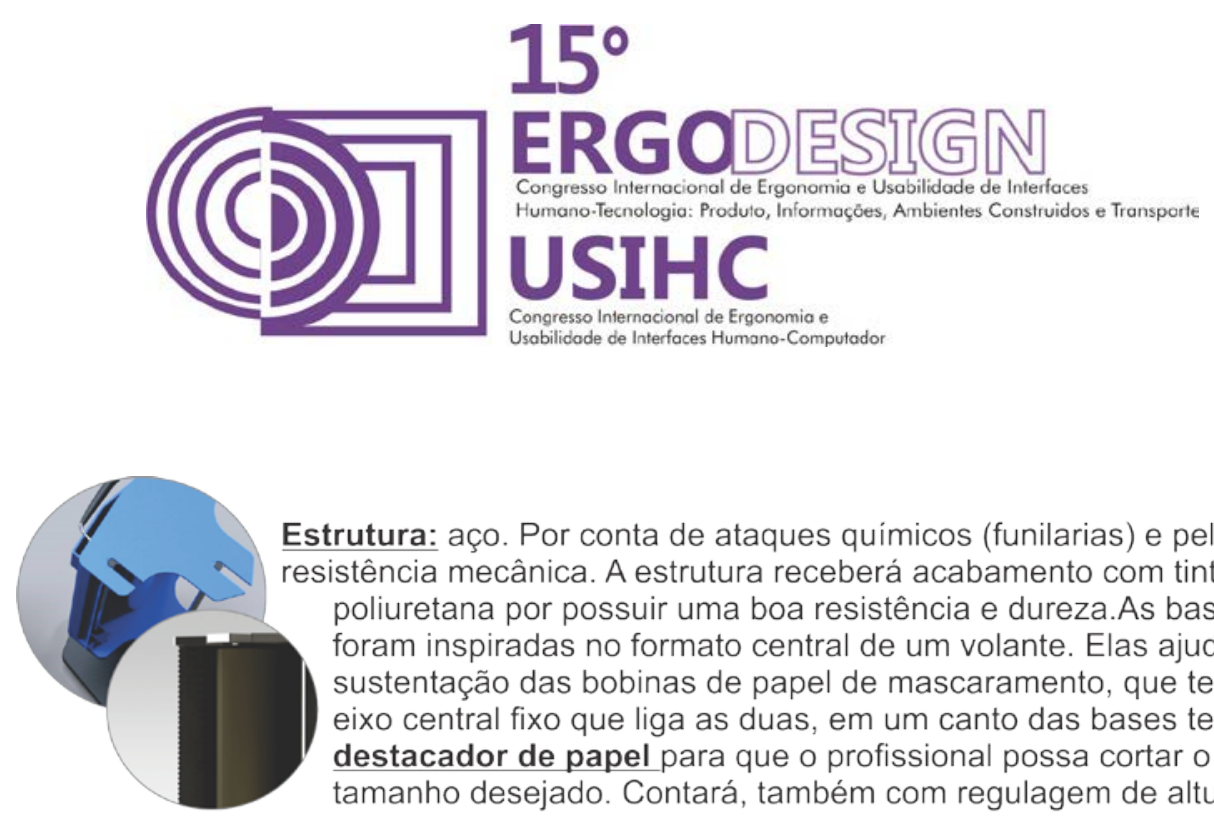

Estrutura: aço. Por conta de ataques quimicos (funilarias) e pela boa resistência mecânica. A estrutura receberá acabamento com tinta poliuretana por possuir uma boa resistência e dureza.As bases foram inspiradas no formato central de um volante. Elas ajudam na sustentação das bobinas de papel de mascaramento, que tem o eixo central fixo que liga as duas, em um canto das bases terá o destacador de papel para que o profissional possa cortar o tamanho desejado. Contará, também com regulagem de altura.

Haste: a medida da haste será baseada na bobina de papel de 90 $\mathrm{cm}$, independente as outras bobinas de medidas menores, para que haja um equilíbrio no dispensador. Em relação à troca de bobina, as hastes terão um ressalto na parte inferior para que a bobina não venha se encostar-se às paredes laterais. Haverá um furo nas hastes na qual passará um pino que ligará as hastes a duas paredes, esse

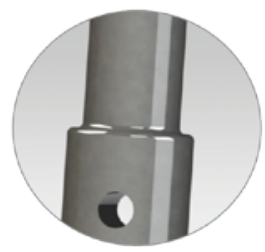
furo é para que a haste se movimente para trás e para frente e quando o profissional for trocar a bobina ele vai desencaixar da base superior à haste que se inclinará a uma parede com um pé de apoio a um ângulo favorável para a colocação de uma nova bobina.

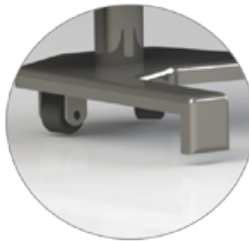

Pé de apoio: para que não venha a cair o dispensador na hora de destacar o papel, a base terá dois pés de apoio. A parte de baixo da base é vazada, ressaltando que os pés tem o comprimento maior que da base superior em relação à gravidade e também por uma boa fixação para que não se mova ao destacar o papel de mascaramento. Contará, também, com rodízios para facilitar a movimentação.

Pega: Como no dispensador vendido hoje no mercado à pega possui uma adequação apenas para uma das mãos do profissional para manuseá-lo, nessa nova proposta de dispensador foi elaborada uma pega com a medida adequada ao profissional, utilizando um cano tubular e passado por uma dobradeira obtendo o formato ideal, onde possam ser manuseadas pela as duas mãos.

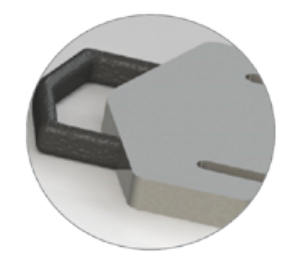

Figura 8 - Detalhes da proposta de dispensador de papel de mascaramento Fonte: do autor (2013)

\section{CONCLUSÃO}

Com base nos estudos aplicados no projeto, observar-se que é de grande valia o papel do designer no desenvolvimento de produtos, partindo desde pesquisa, relação direta com as pessoas, contato direto com material e até mesmo no processo de fabricação de um novo produto.

Diante deste projeto pode-se concluir que a Ergonomia está presente em todo nosso cotidiano, levando em consideração os benefícios que ela nos traz visando adaptação das atividades humanas em relação saúde e bem estar. Atualmente, tornou-se cotidiano, trabalhadores se 


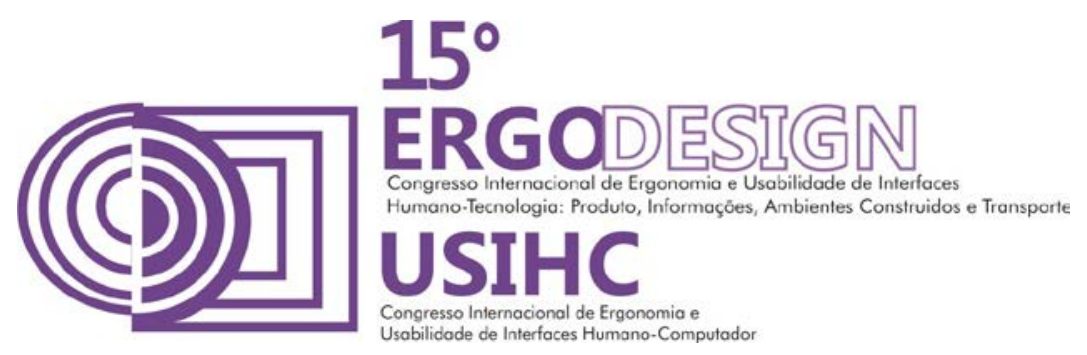

afastarem de suas funções devido às dores na coluna ou dores similares. Isso ocorre em relação à postura inadequada que exercem. Mas, para evitar tais transtornos, esta situação deve ser revisada e transformada com o auxílio da Ergonomia, atuando nas ferramentas até mesmo no posto de trabalho.

O interessante foi transmitir aos leitores a importância do papel do Design no desenvolvimento de um produto e acima de tudo no cotidiano das pessoas. Todo o contexto do projeto serviu como conhecimentos que serão relevantes não só para esse ambiente (funilarias), em particular, mas a todos os ambientes profissionais que necessitam de melhorias nos projetos de ferramentas e equipamentos.

\section{REFERÊNCIAS BIBLIOGRÁFICAS}

CARDOSO, Nany. Massas: evolução constante. In: NETO, Agnelo de Barros. Revista Lojas Tintas Imobiliárias e Repintura Automotiva, São Paulo, ano 15, n. 121, ago. 2012, 58-60 pp.

DUL, Jean; WEERDMEESTER, Bernard. Ergonomia Prática. Tradutor: Itiro lida. 3. ed. rev. São Paulo: Blucher, 2012. 147 p.

IIDA, Itiro. Ergonomia: projeto e produção. 2 ed.rev. e ampl. São Paulo: Edgard Blucher, 2005, 465 p.

LOBACH, A Bernd. Design Industrial: bases para a configuração dos produtos industriais. São Paulo: Edgard Blucher, 2001, 205 p.

SAVARIZ, Manoelito. C. Manual de Produtos Perigosos: Emergência e Transporte. 2a Ed. Porto Alegre: Sagra, 1994.

SERRANO, Daniel Portillo. Análise SWOT: a matriz fofa - análise PFOA. [S.I.s.n], 2011. Disponível em: < http://www.portaldomarketing.com.br/Artigos/Analise_SWOT_Matriz_FOFA.htm>. Acesso em: 31 jul. 2013.

SOARES, Felipe Cantório. Estudo de caso: otimização do ensino de informática através da aplicação dos conceitos de ergonomia no ambiente físico. Dissertação (Mestre) - Programa de Pós-Graduação em Engenharia de Produção. Florianópolis: Universidade Federal de Santa Catarina, 1999. 130 p.

VASCONCELOS, Bruna Mara; FRANCISCO, Débora Alice; MOREIRA, Glória M. S. Noções de Ergonomia na Oficina Mecânica do IFECT do Sul de Minas. Monografia (Técnico em Enfermagem do Trabalho) - Curso Técnico em Enfermagem do Trabalho. Muzambinho: Instituto Federal de Educação, Ciência e Tecnologia do Sul de Minas, 2011, 26 p. 